\section{Seedling Growth of Catawba Rhododendron. II. Photosynthesis and Carbohydrate Accumulation and Export}

\author{
D. Bradley Rowe', Stuart L. Warren ${ }^{2}$, Frank A. Blazich ${ }^{3}$, and \\ D. Mason Pharr ${ }^{3}$ \\ Department of Horticultural Science, North Carolina State University, Raleigh, \\ NC 27695-7609
}

Additional index words. Rhododendron catawbiense, native plants, Ericaceae, thermoperiod, temperature optima, provenance

\begin{abstract}
Catawba rhododendron (Rhododendron catawbiense Michx.) seedlings of two provenances, Johnston County, N.C. $\left(35^{\circ} 45^{\prime} \mathrm{N}, 7^{\circ} 12^{\prime} \mathrm{W}\right.$, elevation $\left.=67 \mathrm{~m}\right)$, and Yancey County, N.C. $\left(35^{\circ} 45^{\prime} \mathrm{N}, 8^{\circ} 16^{\prime} \mathrm{W}\right.$, elevation $\left.=1954 \mathrm{~m}\right)$, were grown in controlled-environment chambers for 18 weeks with days at $18,22,26$, or $30 \mathrm{C}$ in factorial combination with nights at 14, 18, 22, or 26C. Seedlings of the higher-elevation provenance generally exhibited higher net leaf photosynthetic rates $\left(P_{N}\right)$ s than those from the lower elevation at all temperature combinations. Thus, it appears seedlings of the high-elevation provenance possess greater relative thermotolerance, expressed as net photosynthesis, than the lowelevation provenance. Eighty-seven days after initiation (DAI) of the experiment, $P_{N}$ showed a quadratic response to increasing day temperature, with the maximum occurring at 22C, whereas $P_{N}$ decreased linearly with increasing night temperature. At 122 DAI, $P_{N}$ increased linearly with increasing day temperature with nights at 22 and $26 C$. Highest $P_{N} S$ were at 30/22C and $26 / 22 \mathrm{C}$. Carbohydrate export increased with increasing day temperature, whereas the response to night temperature was minimal. High levels of nonstructural carbohydrates occurred at thermoperiods $(22 / 22 \mathrm{C}$ and $26 / 22 \mathrm{C})$ that optimize seedling growth. However, definitive trends relating seedling growth to $P_{N} s$, leaf carbohydrate levels, or to the amount of carbohydrate exported from the leaves were difficult to generalize due to numerous day $\times$ night interactions.
\end{abstract}

Catawba rhododendron is an outstanding ericaceous landscape plant that possesses a higher temperature optimum than most species of rhododendron (Leach, 1961; Thornton, 1990). Its southern range, however, is still limited due to factors such as high night temperatures (Harden, 1990). Thus, it would be desirable to extend the southern range of catawba rhododendron by identifying provenances possessing a higher temperature optimum for growth.

Recently, Rowe et al. (1994) compared seedling growth of a high- and a low-elevation provenance of the species exposed to 16 thermoperiods. Dry weights for the entire plant, shoots, and roots, and total leaf area of seed-

Received for publication 9 Dec. 1993. Accepted for publication 10 June 1994. This research was funded by the North Carolina Agricultural Research Service (NCARS), Raleigh. Use of trade names in this publication does not imply endorsement by the NCARS of products named, nor criticism of similar ones not mentioned. From a thesis submitted by D.B.R. in partial fulfillment of the MS degree requirements. Assistance of William M. Reece, Mara O. Massel, Johan M. Stoop, and the staff of the Southeastern Plant Environment Laboratory is gratefully acknowledged. The cost of publishing this paper was defrayed in part by the payment of page charges. Under postal regulations, this paper therefore must be hereby marked advertisement solely to indicate this fact.

${ }^{1}$ Graduate Research Assistant.

${ }^{2}$ Associate Professor.

${ }^{3}$ Professor. lings of the high-elevation provenance exceeded those of the low-elevation provenance at all temperature combinations. These results seem to indicate that the low-elevation provenance does not exhibit a higher temperature optimum for growth than the other provenance. The basis for the relatively high temperature optimum of the high-elevation provenance is intriguing and may be related to photosynthetic processes.

Doorenbos (1955) reported that plants of catawba rhododendron grown under photoperiods of 18 to $24 \mathrm{~h}$ grew twice as fast as plants grown under natural daylength. Nilsen (1987) investigated the effects of temperature and water stress on leaf curling of rosebay (Rhododendron maximum L.) and catawba rhododendrons. However, to our knowledge, no research has been reported to date on photosynthetic and related processes in catawba rhododendron as influenced by temperature. $\mathrm{We}$, therefore, examined the effects of selected thermoperiods on photosynthetic rates, leaf carbohydrate levels, and carbohydrate export as they influence seedling growth of two provenances of catawba rhododendron.

\section{Materials and Methods}

Mature seed capsules were collected from native stands of open-pollinated plants of catawba rhododendron growing in Johnston County, N.C. $\left(35^{\circ} 45^{\prime} \mathrm{N}, 78^{\circ} 12^{\prime} \mathrm{W}\right.$, elevation $=$ $67 \mathrm{~m})$, and Yancey County, N.C. $\left(35^{\circ} 45^{\prime} \mathrm{N}\right.$, $82^{\circ} 16^{`} \mathrm{~W}$, elevation $=1954 \mathrm{~m}$ ), on 31 Oct. and 20 Nov. 1989, respectively. Following collection, seeds were dried and stored as described by Rowe et al. (1994).

Seeds of both provenances, removed from storage on 10 Jan. 1990, were germinated and grown in a greenhouse for 22 months (Rowe et al., 1994). At 646 days after germination, uniform seedlings were transferred to the Southeastern Plant Environment Laboratory (Phytotron) where 16 thermoperiods were initiated the following day (day 0) using controlled-environment A-chambers (Downs and Thomas, 1983). Plants were arranged in a $4 \times$ 4 factorial in a completely random design using nine single-plant replications per temperature treatment per provenance. The two main factors were day $(18,22,26$, and 30C) and night $(14,18,22$, and 26C) temperatures provided to seedlings as $9 / 15$-h thermoperiods. Phytotron cultural conditions were described by Rowe et al. (1994).

Eighty-seven and 122 days after initiation (DAI), leaf disk samples were taken with a cork borer (2.5 cm in diameter) (Fisher \#9; Fisher Scientific, Pittsburgh) from five plants within each treatment per provenance. At the beginning of the photoperiod (0800 HR), one disk was obtained from each of three separate, recently matured leaves on the same plant (i.e., AM samples). At the end of the photoperiod (1700 HR), one additional disk was obtained from the opposite side of the midvein of each leaf sampled that morning (i.e., PM samples). A total of 240 leaf disks (16 treatments $\times$ five plants per treatment $\times$ three disks per plant $=$ 240) was collected for each sample time within each provenance at 87 and 122 days after initiation (DAI). Disks were placed immediately in vials packed in ice and frozen at $-20 \mathrm{C}$. Samples were then freeze-dried for 3 days, weighed to the nearest $0.0001 \mathrm{~g}$, and stored in desiccators for further analysis.

Between 1000 and $1400 \mathrm{HR}$ on the same days that leaf disks were collected, leaf gas exchange was measured with a LI-6200 closed portable infrared gas-exchange system (LICOR, Lincoln, Neb.). Photosynthetically active radiation, air and leaf temperatures, and relative humidity inside the leaf chamber were measured concurrently with gas exchange. Net leaf photosynthetic rates $\left(\mathrm{P}_{\mathrm{N}}\right) \mathrm{s}$ were calculated using the LI-COR 6200 measurements. Data were recorded from a recently matured leaf on each of three plants per temperature treatment per provenance using a 0.25 -liter chamber for $30 \mathrm{sec}$. Vapor pressure deficits within the chamber were $0.92,1.20,1.31$, and $1.71 \mathrm{kPa}$ at $18,22,26$, and $30 \mathrm{C}$, respectively. Measurements commenced immediately after the $\mathrm{CO}_{2}$ concentration decreased in the chamber. Average $\mathrm{CO}_{2}$ concentration was 350 $\mu \mathrm{mol} \cdot \mathrm{mol}^{-1}$, and steady-state $\mathrm{P}_{\mathrm{N}} \mathrm{s}$ were assumed. Carbohydrate export from leaves was calculated by subtracting dry weight gain per leaf disk sample (PM leaf disk dry weight - AM leaf disk dry weight) from the gain in fixed $\mathrm{C}$ expected from the measured $\mathrm{P}_{\mathrm{N}}$.

Starch content was determined for those leaf disks collected 122 DAI from plants grown at all day temperatures in combination with 
nights of 14 and 22C. These samples were chosen because these night temperatures exhibited the greatest impact on growth and dry matter accumulation (Rowe et al., 1994). Disks were ground with a mortar and pestle and extracted three times with $80 \%$ (v/v) ethanol. The remaining insoluble residue was resuspended in $1 \mathrm{ml} 30 \mathrm{~mm} \mathrm{HCl}$ and boiled for 30 min. After cooling, $\mathrm{pH}$ was adjusted to 4.5 using $\mathrm{KOH}$. The gelatinized starch was digested for $60 \mathrm{~min}$ at $55 \mathrm{C}$ using 36 units amyloglucosidase [from Aspergillus oryzae (Ahlburg) Cohn.]. The amyloglucosidase had previously been dialyzed against $50 \mathrm{~mm} \mathrm{Na-}$ acetate buffer ( $\mathrm{pH} 4.5)$. Samples were boiled for $1 \mathrm{~min}$ to stop the reaction. After cooling and centrifugation, an aliquot of the superna- tant was used to measure glucose in a solution (1 ml) containing $100 \mathrm{~mm}$ Hepes- $\mathrm{NaOH}(\mathrm{pH}$ 8.0), $5 \mathrm{~mm} \mathrm{MgCl}_{2}, 1 \mathrm{~mm}$ NAD, 1 mм ATP, 5 mm DTT, 2.5 units hexokinase (from baker's yeast), and 2.5 units Glc 6-P dehydrogenase [from Leuconostoc mesenteroides (Tsenkovskii) van Tieghem]. The reaction mixture was incubated at $25 \mathrm{C}$ for $30 \mathrm{~min}$, and its absorbance at $340 \mathrm{~nm}$ was measured on an ultraviolet max kinetic microplate reader (Molecular Devices Corp., Menlo Park, Calif.) to determine starch content. Data were subjected initially to analysis of variance procedures. Linear and quadratic regression equations were then fit to the data, and correlations among specified variables were examined (SAS Institute, 1990).

\section{Results and Discussion}

High-elevation seedlings generally exhibited higher $\mathrm{P}_{\mathrm{N}} \mathrm{s}$ than low-elevation seedlings at all thermoperiods 87 DAI, but seedlings of the high-elevation provenance exhibited higher $\mathrm{P}_{\mathrm{N}} \mathrm{s}$ at all 16 temperature combinations 122 DAI (data not presented). These data agree with those of Ledig and Korbobo (1983), who reported $\mathrm{P}_{\mathrm{N}} \mathrm{s}$ of sugar maple (Acer saccharum Marsh.) were highest in progeny from highelevation seedlings regardless of the growth temperature. However, Slatyer and Ferrar (1977) reported optimum temperature for photosynthesis decreased with increasing elevation for three provenances of snow gum $(E u$ calyptus pauciflora Sieber ex Spreng.). Simi-

Table 1. Effect of day/night temperature on net leaf photosynthetic rate, specific leaf weight, $\mathrm{C}$ gain, carbohydrate export, and starch accumulation in seedlings of catawba rhododendron 87 and 122 days after initiation (DAI) of the experiment.

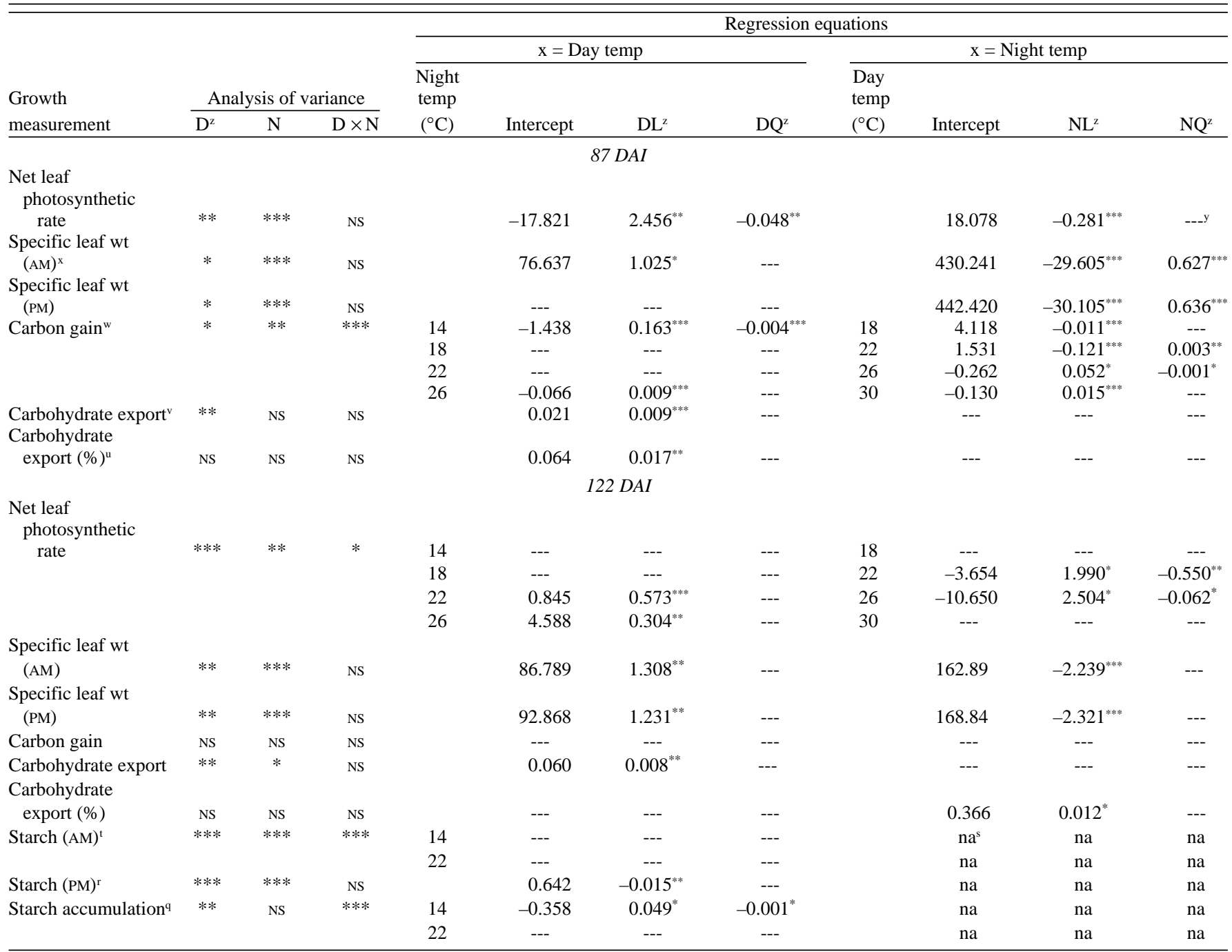

${ }^{2} \mathrm{D}=$ day temperature, $\mathrm{N}=$ night temperature, $\mathrm{D} \times \mathrm{N}=$ interaction of day and night temperature, $\mathrm{DL}=$ day temperature (linear), $\mathrm{DQ}=$ day temperature (quadratic),

$\mathrm{NL}=$ night temperature (linear), $\mathrm{NQ}=$ night temperature (quadratic).

yesponse was nonsignificant (NS).

${ }^{\mathrm{x}}$ Specific leaf weight $=$ milligrams leaf dry weight per square centimeter.

${ }^{\mathrm{w}}$ Carbon gain $=$ specific leaf weight $(\mathrm{PM})-$ specific leaf weight $(\mathrm{AM})$.

${ }^{\vee}$ Carbohydrate export $=$ milligrams carbohydrate exported from leaf per square centimeter per second.

"Carbohydrate export $(\%)=$ percent fixed $\mathrm{CO}_{2}$ exported from leaf.

${ }^{\mathrm{t}}$ Starch $(\mathrm{AM})=$ milligrams starch per square centimeter at beginning of photoperiod.

sNot applicable.

${ }^{\mathrm{r}} \mathrm{Starch}(\mathrm{PM})=$ milligrams starch per square centimeter at end of photoperiod

${ }^{9}$ Starch accumulation $=$ starch $(\mathrm{PM})-\operatorname{starch}(\mathrm{AM})$.

Ns, *,******N Nonsignificant or significant at $P \leq 0.10,0.05$, or 0.01 , respectively. 
lar results were reported by Fryer and Ledig (1972) for balsam fir [Abies balsamea (L.) Mill.] for which plant dry weights were correlated with $\mathrm{P}_{\mathrm{N}} \mathrm{s}$. Although $\mathrm{P}_{\mathrm{N}} \mathrm{s}$ are not always well correlated with growth, Friend and Helson (1976) reported that increased growth rates at elevated day temperatures resulted from higher $\mathrm{P}_{\mathrm{N}} \mathrm{s}$.

While the quantity of exported carbohydrate was also greater for high-elevation seedlings of catawba rhododendron at all temperature combinations 87 DAI, no such differences were detected in low-elevation seedlings 122 DAI (data not presented). Similarly, highelevation seedlings had higher shoot and total plant dry weights at all thermoperiods (Rowe et al., 1994). Thus, it appears that progeny from high-elevation seed of catawba rhododendron possess a higher temperature optimum for growth and greater relative thermotolerance in respect to $\mathrm{P}_{\mathrm{N}} \mathrm{s}$.

These results support those by Konovalov and Mikhaleva (1955) who reported a strong correlation between $\mathrm{P}_{\mathrm{N}} \mathrm{s}$ of seedlings of Persian walnut (Juglans regia L.) and their geographic origin. Seed collected from colder areas resulted in plants with high photosynthetic capacity and high tolerance to environmental changes. In addition, at high altitudes, which are characterized by short growing seasons, high rates of $\mathrm{C}$ assimilation could be favored by natural selection (Ledig and Korbobo, 1983). In climatically unfavorable years with late springs, dry summers, or early autumns, survival could depend on the capacity to produce and accumulate carbohydrates during relatively short periods (Ledig and Korbobo, 1983).

No significant interactions with provenances occurred; therefore, data were averaged over both provenances and reanalyzed by sampling time to provide information regarding photosynthetic rates, carbohydrate export, and starch accumulation.

Net leaf photosynthetic rates were influenced by day and night temperature, and a significant day $\times$ night $(\mathrm{D} \times \mathrm{N})$ interaction occurred 122 DAI (Table 1). At 87 DAI, $\mathrm{P}_{\mathrm{N}}$ showed a quadratic response to day temperature, with the maximum occurring at $22 \mathrm{C}$, whereas $\mathrm{P}_{\mathrm{N}}$ decreased linearly with increasing night temperature (Fig. 1A). At 122 DAI, $\mathrm{P}_{\mathrm{N}}$ increased linearly with increasing day temperature with nights at 22 and 26C (Fig. 1B) and exhibited a quadratic response at 22 and 26C days (Table 1). Kramer and Kozlowski (1979) reported that $\mathrm{P}_{\mathrm{N}} \mathrm{s}$ of most woody plants increased with increasing temperature within moderate temperature ranges. Net leaf photosynthetic rates were not affected by day temperature at 14 or $18 \mathrm{C}$ nights. Highest $\mathrm{P}_{\mathrm{N}} \mathrm{S}$ were observed at 30/22C and 26/22C (Fig. 1B), whereas shoot dry weight was highest at 26/ $18 \mathrm{C}$ and 22/22C (Rowe et al., 1994). This is not surprising since net photosynthesis on a per leaf basis is seldom correlated with growth (Friend and Helson, 1976). However, one might expect growth to be correlated with the $\mathrm{P}_{\mathrm{N}}$ of the entire canopy. In work with other ericaceous species, Malek et al. (1992a) reported that growth and $\mathrm{P}_{\mathrm{N}} \mathrm{s}$ for flame azalea [Rhodo- dendron calendulaceum (Michx.) Torr] were not correlated. However, the two variables were maximized at the same temperature for mountain laurel (Kalmia latifolia L.) (Malek et al., 1992b).

Except for PM specific leaf weight at 87 DAI, AM and PM specific leaf weights (milligrams dry weight per square centimeter) increased linearly with increasing day temperature at 87 and 122 DAI (Table 1, Fig. $2 \mathrm{~A}$ and B). However, with increasing night temperatures, specific leaf weights showed a quadratic response at 87 DAI and a linear decrease at 122 DAI. Evening (PM) specific leaf weights were higher than morning (AM) specific leaf weights for all thermoperiods. We assume that increases in specific leaf weight as a result of net photosynthesis are attributable to an increase in carbohydrates.
Leaf disk $\mathrm{C}$ gain (of nonstructural carbohydrates) was affected by day and night temperature at $87 \mathrm{DAI}$, and a significant $\mathrm{D} \times \mathrm{N}$ interaction also occurred at this time (Table 1 ). Carbon gain showed a quadratic response to day temperature with nights at $14 \mathrm{C}$, with a maximum for days at $22 \mathrm{C}$ (Fig. 3). In contrast, $\mathrm{C}$ gain increased linearly with increasing day temperature with nights at $26 \mathrm{C}$, with the maximum at $30 \mathrm{C}$, and was relatively constant with nights at 18 and 22C. Carbon gain increased linearly with increasing night temperature when days were at $30 \mathrm{C}$. The greatest $\mathrm{C}$ gain occurred at 22/14C, with the lowest at 30/14C (Fig. 3). The 30/14C thermoperiod also resulted in the lowest shoot dry weight (Rowe et al., 1994). Carbon gain was not affected by temperature 122 DAI (Table 1).

Carbohydrates produced by photosynthe-
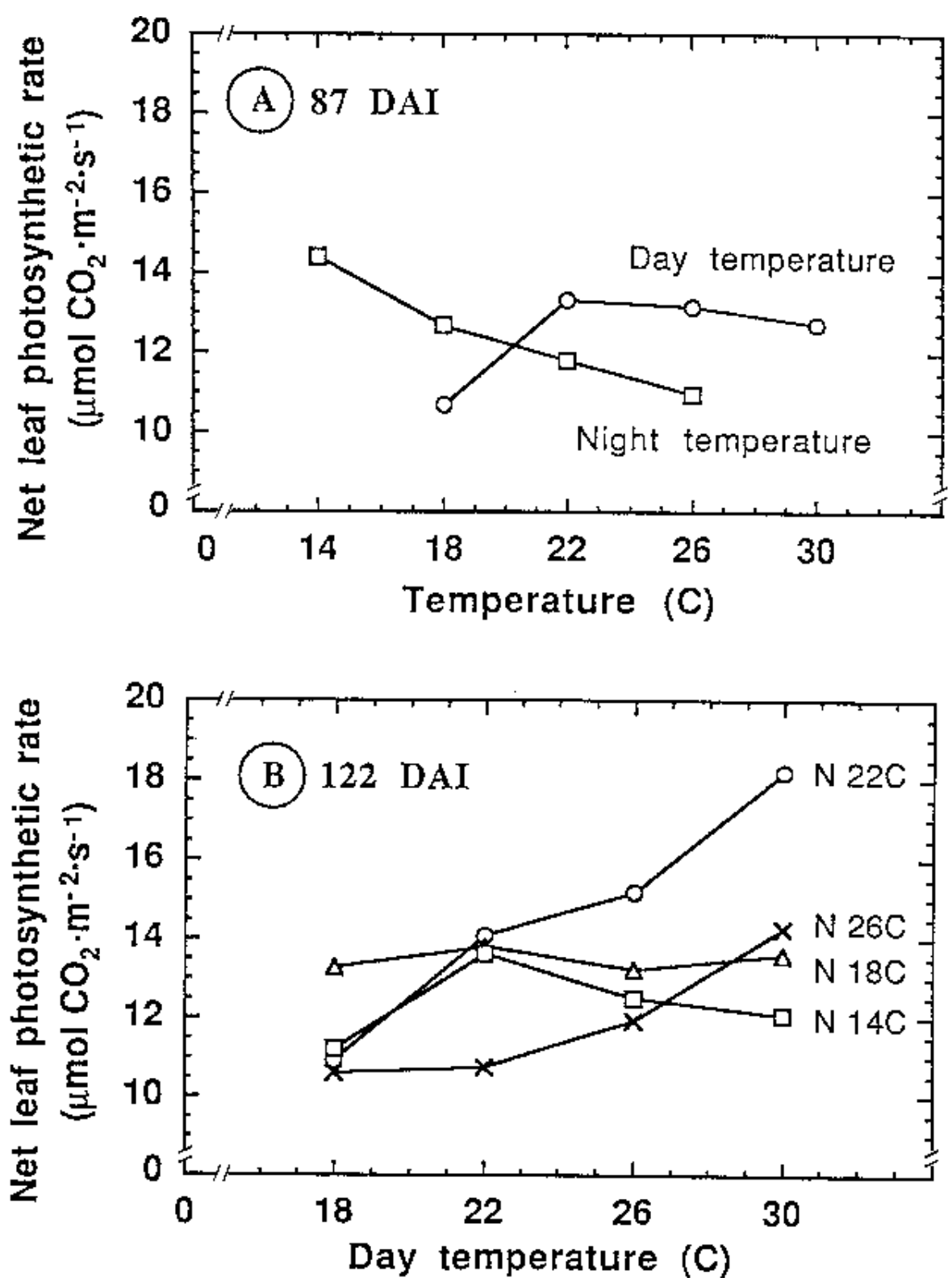

Fig. 1. Effects of day and night $(\mathrm{N})$ temperature on net leaf photosynthetic rate of catawba rhododendron seedlings. (A) 87 and (B) 122 days after initiation (DAI) of the experiment. In A, [effects of day temperature (averaged over night temperatures) and night temperature (averaged over day temperatures)], each symbol represents a mean of 24 observations; in B, each symbol is a mean of six observations. 

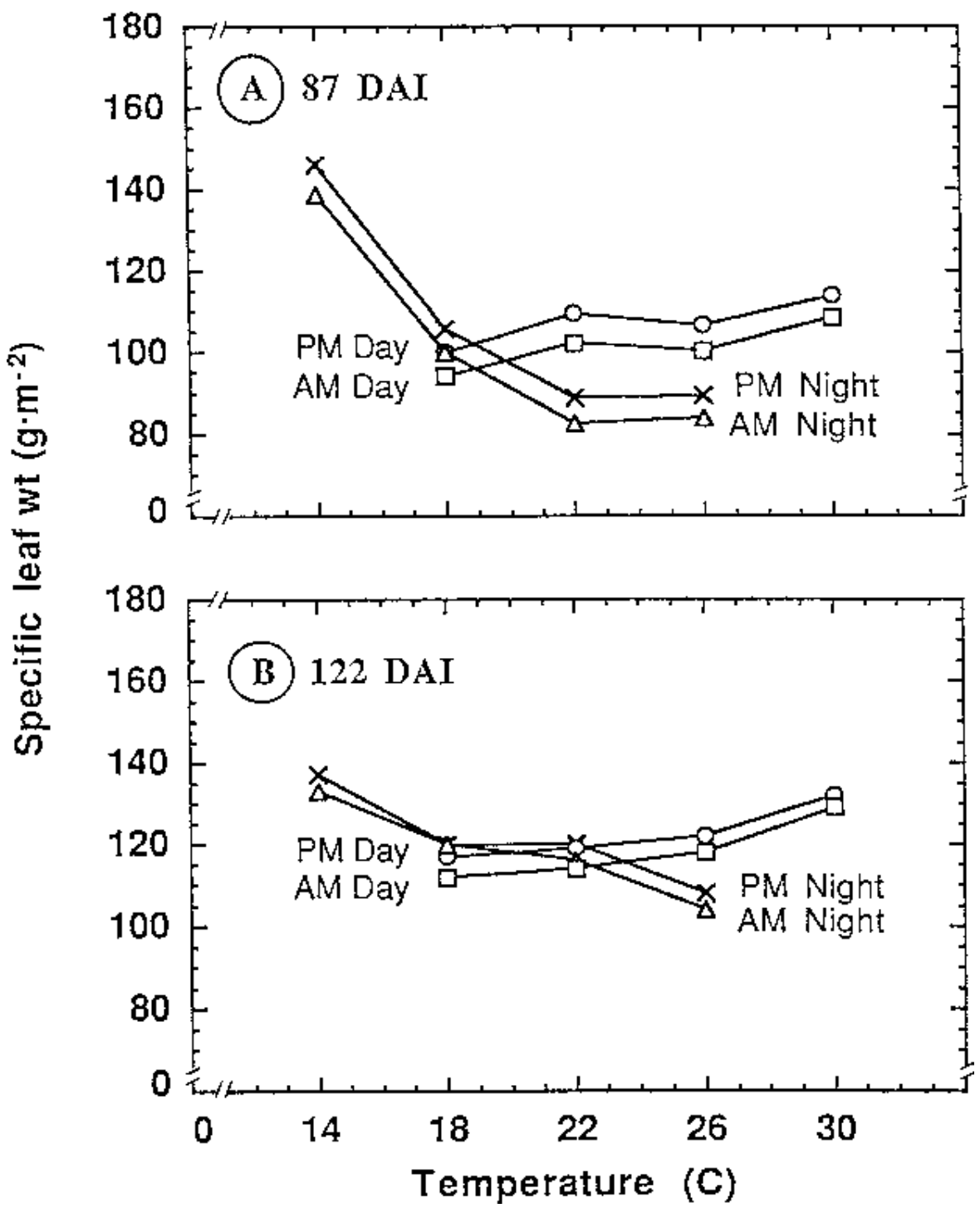

Fig. 2. Effects of day and night $(\mathrm{N})$ temperature on AM and PM specific leaf weights of catawba rhododendron seedlings. (A) 87 and (B) 122 days after initiation (DAI) of the experiment. In A and B [effects of day temperature (averaged over night temperatures) and night temperature (averaged over day temperatures)], each symbol represents a mean of 120 leaf disks.

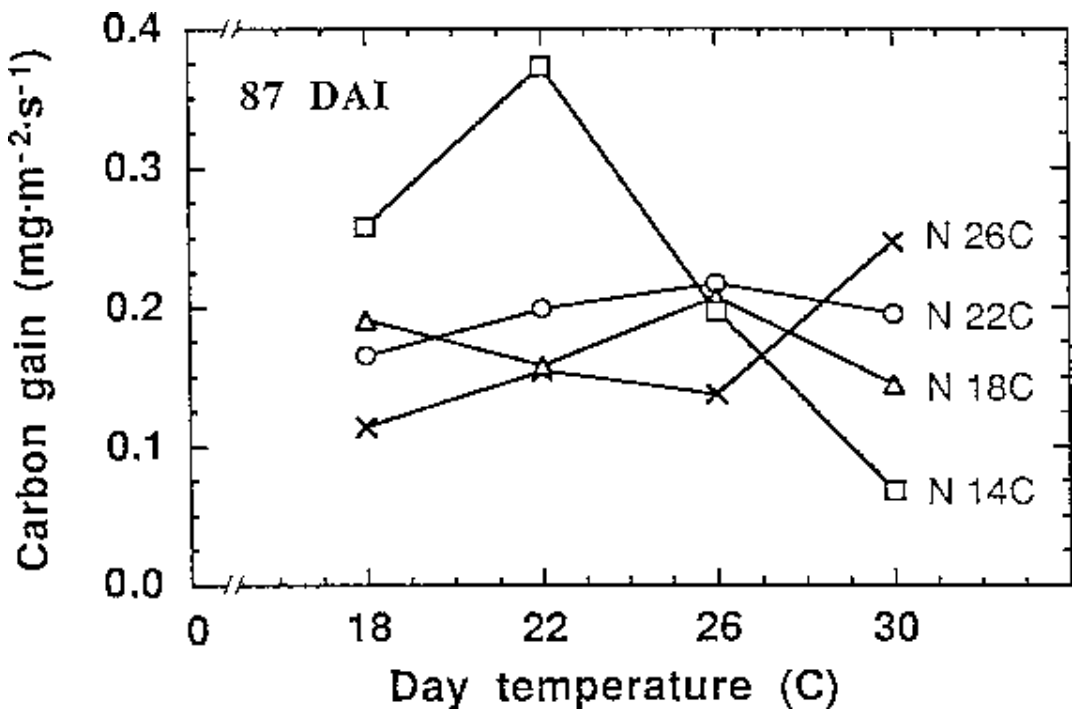

Fig. 3. Effects of day and night $(\mathrm{N})$ temperature on $\mathrm{C}$ gain of catawba rhododendron seedlings at 87 days after initiation (DAI) of experiment. Each symbol is a mean of 30 leaf disks.

sis can be either exported from the leaf, consumed in respiration, or accumulated in leaves for subsequent use (Kramer and Kozlowski, 1979). Carbohydrate export from leaves depended primarily on day temperature (Table 1). Carbohydrate export increased linearly with increasing day temperature for both sample times (Fig. 4), whereas the response to night temperature was minimal, even though it was significant $(P \leq 0.10)$ at 122 DAI (data not presented).

The percentage of fixed $\mathrm{C}$ exported from leaves [carbohydrate export (\%)] increased with increasing day temperature 87 DAI (Fig. 5) and with increasing night temperature 122 DAI. The percentage was highest at a 30/26C thermoperiod for both sample times. Reduced export of $\mathrm{C}$ from leaves at lower temperatures may indicate low sink demand as well as a restriction of phloem translocation (Geiger and Sovonick, 1975; Minchin et al., 1983). Active uptake of sucrose from the apoplast, thought to be the critical step in phloem loading in most species, decreases with decreasing temperature (Giaquinta, 1980). Paul et al. (1990) demonstrated that ${ }^{14} \mathrm{C}$ exported from leaves of sunflower (Helianthus annuus L.), as a proportion of ${ }^{14} \mathrm{CO}_{2}$ fixed, decreased when plants were transferred from 30 to $13 \mathrm{C}$, suggesting that assimilation of $\mathrm{C}$ exceeded utilization more at lower temperatures. Furthermore, Marowitch et al. (1986) reported that bean (Phaseolus vulgaris L.) translocated a smaller proportion of $\mathrm{C}$ fixed in photosynthesis as temperatures decreased from 35 to $4 \mathrm{C}$, supporting the generalization that temperature affects assimilate export more than photosynthesis.

Leaf starch concentrations 122 DAI were influenced by day and night temperatures, and a $\mathrm{D} \times \mathrm{N}$ interaction occurred for morning (AM) starch levels (Table 1). While Am starch levels with nights at $14 \mathrm{C}$ were higher than levels with nights at $22 \mathrm{C}$ for all day temperatures, except 22C (Fig. 6A), PM starch with nights at $14 \mathrm{C}$ was always higher than levels with nights at 22C (Fig. 6B). The slower rate of shoot growth (Rowe et al., 1994) and higher starch content of leaves at 18/14C compared with 26/ $22 \mathrm{C}$ is consistent with the high starch levels found in pangola grass (Digitaria decumbens Stent.) when grown under cool nights (Hilliard and West, 1970). Higher carbohydrate levels would be expected at lower temperatures, as low temperatures depress respiration and new growth so that assimilates are used more slowly (Azcon-Bieto, 1983; Paul et al., 1990). Thus, carbohydrates commonly accumulate in the leaves of plants growing at low temperatures due, in part, to growth being more sensitive to reductions in temperature than photosynthesis (Farrar, 1988).

Starch accumulation during the daily 9-h photoperiod was influenced by a $\mathrm{D} \times \mathrm{N}$ interaction (Table 1). With nights at $14 \mathrm{C}$, starch accumulation peaked with days at $22 \mathrm{C}$ and decreased rapidly at higher day temperatures to the point where, with days at $30 \mathrm{C}$, it was about one-third of the accumulation during nights at $22 \mathrm{C}$ (Fig. 7). Nights of $22 \mathrm{C}$ had less effect, and starch accumulation remained rela- 


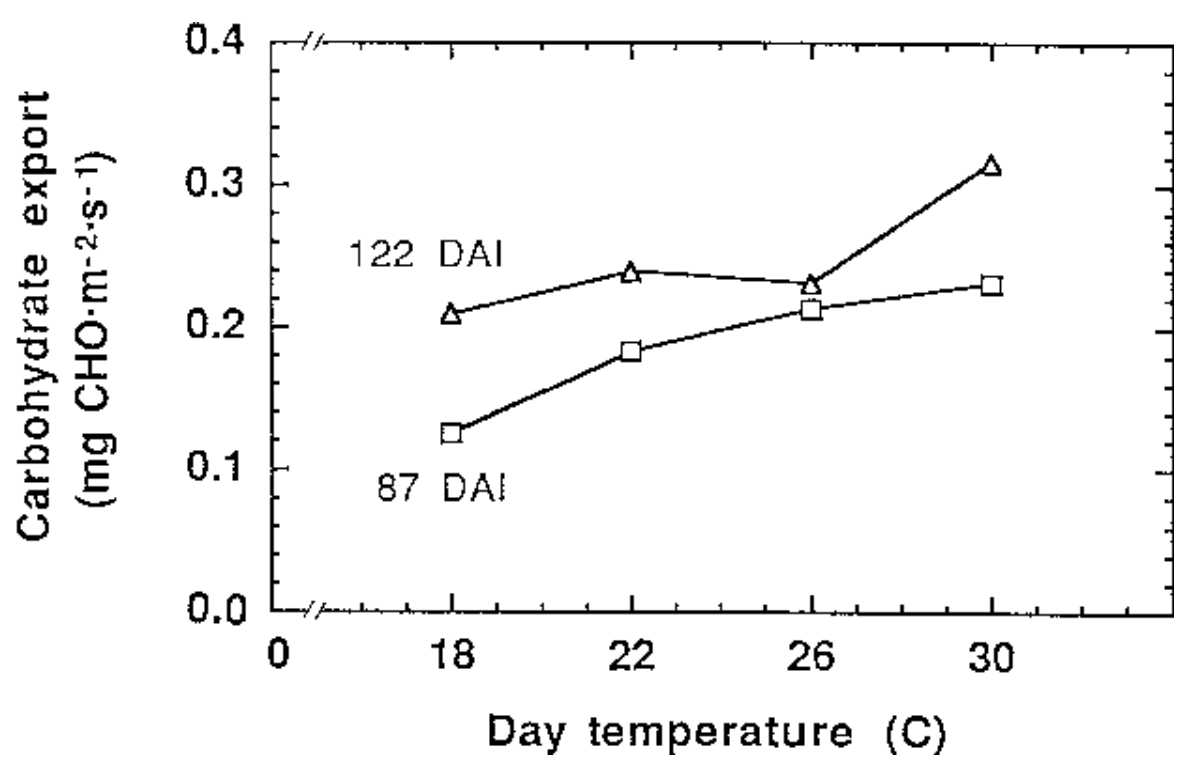

Fig. 4. Effects of day temperature on carbohydrate export from catawba rhododendron seedlings 87 and 122 days after initiation (DAI) of the experiment. Values are calculated from specific leaf weights and net leaf photosynthetic rate measurements.

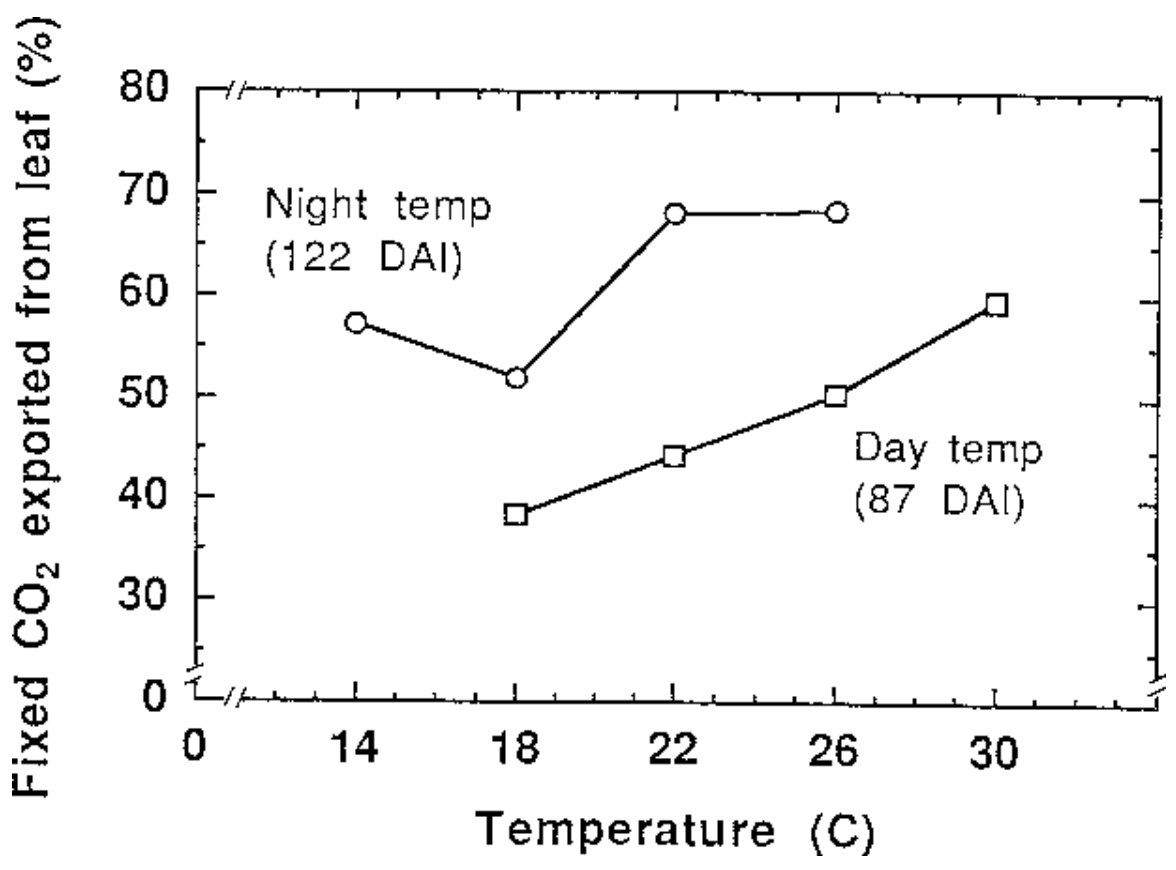

Fig. 5. Effects of day and night temperature on the percentage of fixed $\mathrm{CO}_{2}$ exported from catawba rhododendron seedlings 87 and 122 days after initiation (DAI) of the experiment. Values are calculated from specific leaf weights and net leaf photosynthetic rate measurements.

tively constant over all day temperatures. With days at 22C, starch accumulation was nearly 4 times higher with nights at $14 \mathrm{C}(0.15$ $\left.\mathrm{mg} \cdot \mathrm{m}^{-2} \cdot \mathrm{s}^{-1}\right)$ than at $22 \mathrm{C}\left(0.04 \mathrm{mg} \cdot \mathrm{m}^{-2} \cdot \mathrm{s}^{-1}\right)$. High concentrations of nonstructural carbohydrates were present at thermoperiods of $22 / 22 \mathrm{C}$ and $26 / 22 \mathrm{C}$, which also optimized seedling growth (Rowe et al., 1994).

Although little starch accumulated during the 9-h photoperiod at $30 / 14 \mathrm{C}$, leaves still contained high concentrations of starch, possibly due to growth being limited more by the rate of carbohydrate conversion to new tissues than by the amount of available carbohydrates (Kramer and Kozlowski, 1979). Lower dark respiration rates during nights at $14 \mathrm{C}$ than $22 \mathrm{C}$ may also account for higher starch levels since temperature is the most important environmental factor influencing dark respiration (Levitt, 1980). This conjecture is consistent with the findings of Pasian and Lieth (1989), who reported that rates of dark respiration increased with increasing temperature in rose (Rosa L.) species. The 30/14C thermoperiod also resulted in the lowest leaf area and shoot dry weight (Rowe et al., 1994).

In conclusion, seedlings of the higher-elevation provenance generally exhibited higher $\mathrm{P}_{\mathrm{N}} \mathrm{s}$ than those from the lower elevation at all temperature combinations. Accordingly, seed- lings of the high-elevation provenance seem to possess greater relative thermotolerance, expressed as net photosynthesis, than the lowelevation provenance. Thus, seedlings from the low-elevation provenance may not be suitable for expanding the southern landscape range of catawba rhododendron. Carbohydrate export increased with increasing day temperature, but the response to night temperature was minimal. High concentrations of nonstructural carbohydrates accumulated at thermoperiods $(22 / 22 \mathrm{C}$ and $26 / 22 \mathrm{C})$ that also optimized seedling growth.

\section{Literature Cited}

Azcon-Bieto, J. 1983. Inhibition of photosynthesis by carbohydrates in wheat leaves. Plant Physiol. 73:681-686.

Doorenbos, J. 1955. Shortening the breeding cycle of rhododendron. Euphytica 4:141-146.

Downs, R.J. and J.F. Thomas. 1983. Phytotron procedural manual for controlled environment research at the Southeastern Plant Environment Laboratory. North Carolina Agr. Res. Serv. Tech. Bul. 224 (revised).

Farrar, J.F. 1988. Temperature and the partitioning and translocation of carbon, p. 203-235. In: S.P. Long and F.I. Woodward (eds.). Plants and temperature. Company Biologists, Cambridge, U.K.

Friend, D.J.C. and V.A. Helson. 1976. Thermoperiodic effects on the growth and photosynthesis of wheat and other crop plants. Bot. Gaz. 137:75-84.

Fryer, J.H. and F.T. Ledig. 1972. Microevolution of the photosynthetic temperature optimum in relation to the elevational complex gradient. Can. J. Bot. 50:1231-1235.

Geiger, D.R. and S.A. Sovonick. 1975. Effects of temperature, anoxia and other metabolic inhibitors on translocation, p. 256-286. In: M.H. Zimmermann and J.A. Milburn (eds.). Transport in plants I. Phloem transport. Encyclopedia Plant Physiol. Springer-Verlag, Berlin.

Giaquinta, R. 1980. Mechanism and control of phloem loading of sucrose. Ber. Deutsch Bot. Ges. 93:187-201.

Harden, W. 1990. Growing rhododendrons in warm climates. J. Amer. Rhododendron Soc. 45:140142.

Hilliard, J.H. and S.H. West. 1970. Starch accumulation associated with growth reduction at low temperatures in a tropical plant. Science 168:494-496.

Konovalov, I.N. and E.N. Mikhaleva. 1955. The use of labeled carbon $\left(\mathrm{C}^{14}\right)$ in studying the physiological adaptation of plants to their environment. Bot. Zhurnal 40:411-414.

Kramer, P.J. and T.T. Kozlowski. 1979. Physiology of woody plants. Academic, New York.

Leach, D.G. 1961. Rhododendrons of the world and how to grow them. Charles Scribner's Sons, New York.

Ledig, F.T. and D.R. Korbobo. 1983. Adaptation of sugar maple populations along altitudinal gradients: Photosynthesis, respiration, and specific leaf weight. Amer. J. Bot. 70:256-265.

Levitt, J. 1980. Responses of plants to environmental stresses. 2nd ed. Academic, New York.

Malek, A.A., F.A. Blazich, S.L. Warren, and J.E. Shelton. 1992a. Initial growth of seedlings of flame azalea in response to day/night temperature. J. Amer. Soc. Hort. Sci. 117:216-219.

Malek, A.A., F.A. Blazich, S.L. Warren, and J.E. Shelton. 1992b. Initial growth of seedlings of mountain laurel as influenced by day/night tem- 


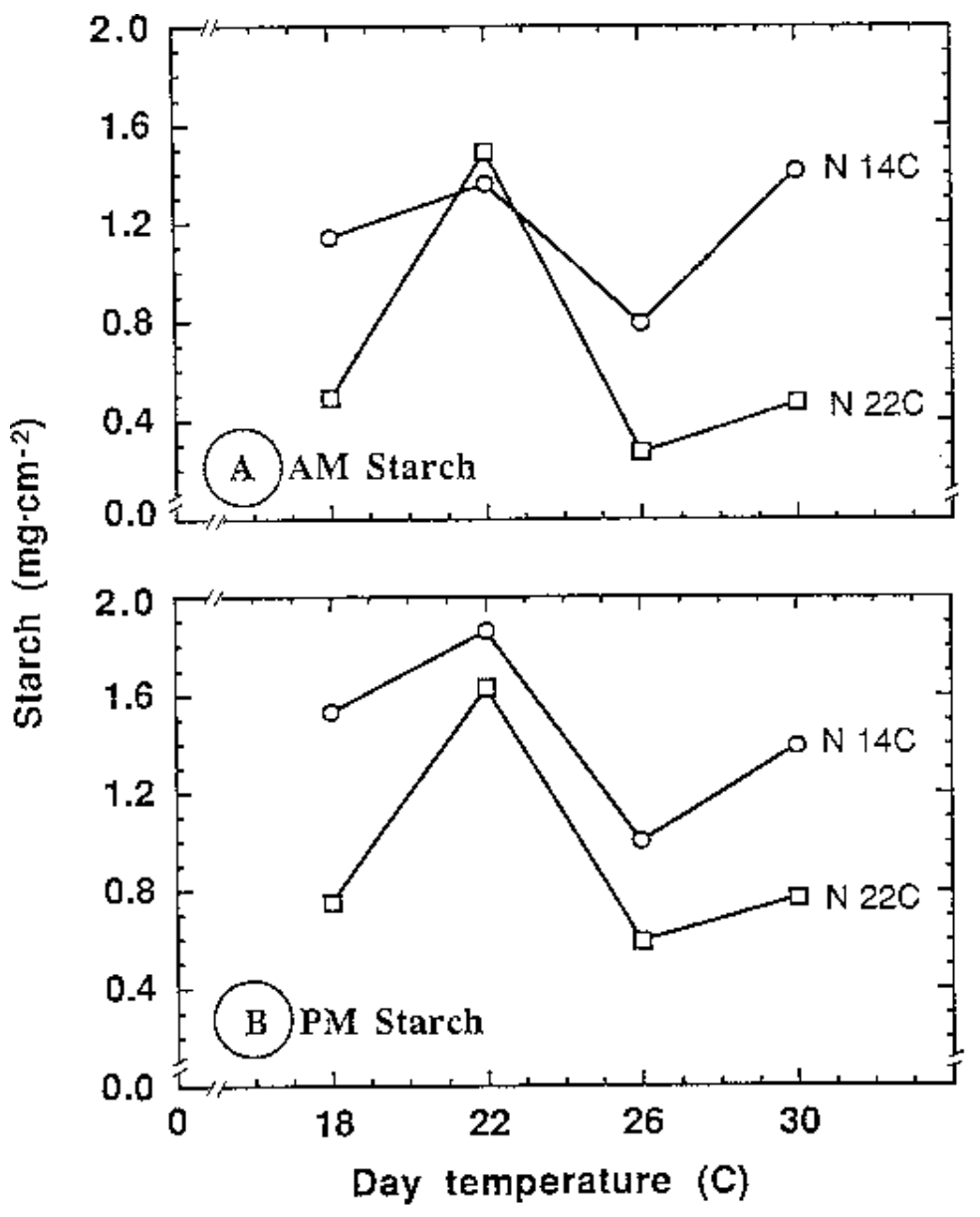

Fig. 6. Effects of day and night $(\mathrm{N})$ temperature on starch content of catawba rhododendron seedlings 122 days after initiation of the experiment. (A) AM starch level and (B) PM starch level. Each symbol is a mean of 30 observations.

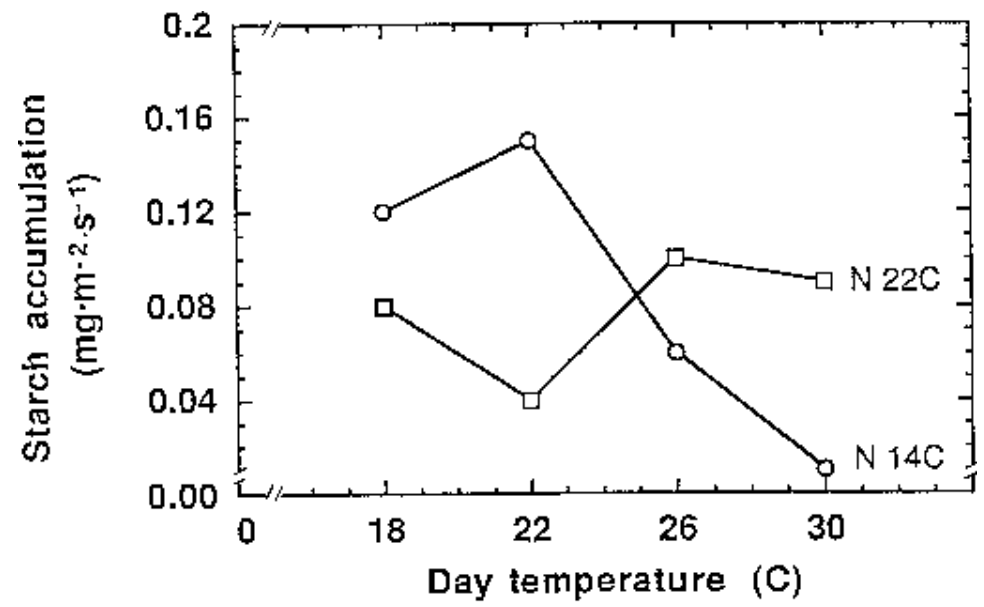

Fig. 7. Effects of day and night $(\mathrm{N})$ temperature on starch accumulation of catawba rhododendron seedlings 122 days after initiation of the experiment. Each symbol is a mean of 30 observations. perature. J. Amer. Soc. Hort. Sci. 117:736-739.

Marowitch, J., C. Richter, and J. Hoddinott. 1986. The influence of plant temperature on photosynthesis and translocation rates in bean and soybean. Can. J. Bot. 64:2337-2342.

Minchin, P.E.H., A. Lang, and M.R. Thorpe. 1983. Dynamics of cold induced inhibition of phloem transport. J. Expt. Bot. 34:156-162.

Nilsen, E.T. 1987. Influence of water relations and temperature on leaf movements of Rhododendron species. Plant Physiol. 83:607-612.

Pasian, C.C. and J.H. Lieth. 1989. Analysis of the response of net photosynthesis of rose leaves of varying ages to photosynthetically active radiation and temperature. J. Amer. Soc. Hort. Sci. 114:581-586.

Paul, M.J., D.W. Lawlor, and S.P. Driscoll. 1990. The effect of temperature on photosynthesis and carbon fluxes in sunflower and rape. J. Expt. Bot. 41:547-555.

Rowe, D.B., S.L. Warren, and F.A. Blazich. 1994. Seedling growth of catawba rhododendron. I. Temperature optima, leaf area, and dry weight distribution. HortScience 29:1298-1302.

SAS Institute. 1990. SAS/STAT user's guide. vol. 2. SAS Inst., Cary, N.C.

Slatyer, R.O. and P.J. Ferrar. 1977. Altitudinal variation in the photosynthetic characteristics of snow gum, Eucalyptus pauciflora Sieb. ex Spreng. II. Effects of growth temperature under controlled conditions. Austral. J. Plant Physiol. 4:289-299.

Thornton, J.T. 1990. Breeding rhododendrons for the Gulf South. J. Amer. Rhododendron Soc. 44(2):91-93. 